\title{
Composição, abundância e diversidade da fauna edáfica em um fragmento de Caatinga
}

A fauna edáfica é usada como bioindicador de qualidade do solo, pois é capaz de transformar o solo, sendo, altamente sensível às modificações ambientais. Possui uma diversidade de invertebrados que vive permanentemente ou que apresenta um ou mais ciclos de vida no solo que variam muito em tamanho e diâmetro, o que Ihes concede habilidades nos métodos de alimentação e adaptação ao hábitat. Assim, objetivou-se identificar e classificar os diferentes grupos da macro e mesofauna do solo, estudar sua abundância e diversidade em dois períodos do ano, em um fragmento de caatinga em Redenção, Ceará. $\mathrm{O}$ estudo foi realizado na Fazenda Experimental (FEP) da Universidade da Integração Internacional da Lusofonia Afro-Brasileira (UNILAB), onde foram instaladas 72 armadilhas para coleta da macro e mesofauna nos períodos seco (2015) e chuvoso (2016). Os organismos capturados foram triados, contados, identificados e classificados em grandes grupos. Foram calculados: densidade e riqueza de grupos e índices de diversidade e uniformidade do solo. Registrou-se 23515 e 18962 indivíduos nos períodos seco e úmido, respectivamente. A riqueza total foi de 43 grupos no período seco e 41 no período chuvoso. Os grupos mais representativos (97\%) pertencem a 12 ordens, distribuídas em quatro classes, sendo Entomobryomorpha, Hymenoptera (Formicidae), Díptera, Acarina, coleóptera e poduromorfa, as mais abundantes. A sazonalidade não alterou composição da fauna edáfica, porém o período chuvoso favoreceu maior diversidade e equabilidade entre os grupos da pedofauna identificados.

\section{Composition, abundance and diversity of edaphic fauna in a Caatinga fragment}

\begin{abstract}
The edaphic fauna is used as a bioindicator of soil quality, as it is capable of transforming the soil, being highly sensitive to environmental changes. It has a diversity of invertebrates that live permanently or that have one or more life cycles in the soil that vary greatly in size and diameter, which gives them skills in methods of feeding and adapting to the habitat. Thus, the objective was to identify and classify the different groups of the soil macro and mesofauna, to study their abundance and diversity in two periods of the year, in a fragment of caatinga in Redenção, Ceará. The study was carried out Experimental Farm (FEP) of the University of International Integration of Afro-Brazilian Lusophony (UNILAB), where 72 traps were installed to collect macro and mesofauna in the dry (2015) and rainy (2016) periods. The captured organisms were screened, counted, identified and classified into large groups. The following were calculated: density and richness of groups and indexes of soil diversity and uniformity. 23515 and 18962 individuals were recorded in the dry and wet periods, respectively. The total wealth was 43 groups in the dry period and 41 in the rainy period. The most representative groups (97\%) belong to 12 orders, distributed in four classes, being Entomobryomorpha, Hymenoptera (Formicidae), Diptera, Acarina, coleoptera and poduromorfa, the most advanced. Seasonality did not alter the composition of the edaphic fauna, but the rainy season favored greater diversity and equability among the identified groups of pedofauna.
\end{abstract}

Keywords: Edaphic arthropod; Maciço de Baturité; Diversity.

Topic: Conservação da Biodiversidade

Reviewed anonymously in the process of blind peer
Received: 02/03/2021

Approved: 24/05/2021
Maria Ivanilda de Aguiar (D)

Universidade da Integração Internacional da Lusofonia Afro-Brasileira, Brasil

http://lattes.cnpq.br/5455983813192128 http://orcid.org/0000-0002-6147-2621 ivanilda@unilab.edu.br

Cesarina Chagas de Freitas (iD)

Universidade da Integração Internacional da Lusofonia Afro-Brasileira, Brasil

http://lattes.cnpq.br/5470918857181523

http://orcid.org/0000-0002-1631-3533

cesarina_chagas@hotmail.com

\section{José Lucas Martins Melo}

Universidade da Integração Internacional da

Lusofonia Afro-Brasileira, Brasil

http://lattes.cnpq.br/3624309239999297

http://orcid.org/0000-0001-9614-9165

jose lucas_martins@hotmail.com

\author{
Beatriz de Araújo Silva (id \\ Universidade da Integração Internacional da \\ Lusofonia Afro-Brasileira, Brasil \\ http://lattes.cnpq.br/0795465486884390 \\ http://orcid.org/0000-0003-1199-6416 \\ beatriz@aluno.unilab.edu.br \\ João Gutemberg Leite Moraes \\ Universidade da Integração Internacional da \\ Lusofonia Afro-Brasileira, Brasil \\ http://lattes.cnpq.br/1063890056906762 \\ http://orcid.org/0000-0002-3340-2191 \\ gutemberg.moraes@unilab.edu.br \\ Fred Denilson Barbosa da Silva (ic) \\ Universidade da Integração Internacional da \\ Lusofonia Afro-Brasileira, Brasil \\ http://lattes.cnpq.br/6158748616979607 \\ http://orcid.org/0000-0002-6365-6045 \\ freddenilson@unilab.edu.br
}

\section{Rafaella da Silva Nogueira (ib) \\ Universidade da Integração Internacional da Lusofonia Afro-Brasileira, Brasil http://lattes.cnpq.br/5709447822168454 http://orcid.org/0000-0001-7540-1173 rafaellanogueira@unilab.edu.br \\ Olienaide Ribeiro de Oliveira Pinto (iD) Universidade da Integração Internacional da Lusofonia Afro-Brasileira, Brasil http://lattes. cnpq.br/8216617581480616 http://orcid.org/0000-0002-8333-3665 agron.olienaide@gmail.com \\ Juan Carlos Alvarado Alcócer (iD) \\ Universidade da Integração Internacional da Lusofonia Afro-Brasileira, Brasil http://lattes.cnpq.br/8172187725052094 http://orcid.org/0000-0003-0722-7040 \\ jcalcocer@unilab.edu.br}

\section{Referencing this:}

AGUIAR, M. I.; FREITAS, C. C.; MELO, J. L. M.; SILVA, B. A.; MORAES, J. G. L.; NOGUEIRA, R. S.; PINTO, O. R. O.; ALCÓCER, J. C. A.. Composição, abundância e diversidade da fauna edáfica em um fragmento de Caatinga. Nature and Conservation, v.14, n.2, p.46-55, 2021. DOI: http://doi.org/10.6008/CBPC2318-2881.2021.002.0005 


\section{INTRODUÇÃO}

A fauna do solo é composta de diversos grupos de invertebrados que vivem pelo menos uma parte de seu ciclo biológico, na serapilheira ou abaixo da superfície. Esta possui organismos de diferentes tamanhos, que podem ser classificados em microfauna, mesofauna e macrofauna, de acordo com seu tamanho corporal (KORASAKI et al., 2013). A macrofauna do solo inclui os invertebrados que apresentam tamanho do corpo maior que $2 \mathrm{~mm}$ de comprimento, enquanto a mesofauna edáfica compreende os organismos de aproximadamente 0,2 e $2 \mathrm{~mm}$ de comprimento (MORAIS et al., 2013).

A mesofauna do solo é composta pelos grupos: Araneae, Acarina, Collembola, Hymenoptera, Díptera, Protura, Diplura, Symphyla, Enchytraeidae, Isoptera, Chilopoda, Diplopoda, Mollusca, Pseudoscorpiones, Pauropoda, Palpigradi, Oligochaetas e Coleoptera (MOÇO et al., 2005; MORAIS et al., 2013). O tamanho desses invertebrados define a extensão em que sua atividade (alimentação e escavação) pode modificar as propriedades do solo; além de como podem ser influenciados pelo manejo adotado (AQUINO et al., 2006). Tais organismos vivem principalmente na camada mais superficial do solo e na serapilheira, onde se encontram restos vegetais (MORAIS et al., 2013). A mesofauna do solo também pode ser classificada, com base em aspectos funcionais, em: i) saprófagos, se alimentam diretamente dos resíduos de plantas, fragmentando-os (Diplopoda, Diplura e Symphyla) e ii) predadores, se alimentam de outros organismos (Chilopoda e Hymenoptera) e larvas de inseto (Díptera, Coleóptera, Lepidóptera e Neuroptera). Os grupos Coleoptera, Collembola e Thysanoptera e os insetos sociais podem ser tanto saprófagos como predadores (MOÇO et al., 2005). A mesofauna atua na decomposição do material depositado sobre o solo, ficando sua atuação mais evidente quando estudada em sistemas de cultivo que conservam a cobertura vegetal do solo, como o plantio direto (MACHADO et al., 2007) e sistemas agroflorestais (LIMA et al., 2010).

Em região semiárida, sob caatinga, os grupos predominantes da mesofauna edáfica são Díptera (42,5\%), Acarina (40,3\%) e Collembola (8,9\%) (SOUTO et al., 2008). Segundo esses autores é provável que os componentes do grupo Díptera sejam agentes importantes na manutenção do equilíbrio ecológico como predadores de alguns organismos edáficos (ácaros, colêmbolas e larvas de coleópteros); sendo assim suas larvas também podem servir de alimento para microrganismos. O grupo dos ácaros apresenta grande diversidade de forma, abundância e diferentes hábitos de alimentação, podendo ser predadores (de outros ácaros, pequenos insetos e nematoides), decompositores e necrófagos (MORAIS et al., 2013).

A macrofauna edáfica compreende alguns invertebrados como minhocas (Oligochaeta), coleópteros (Coleoptera) em estado larval e adulto, centopeias (Chilopoda), cupins (Isoptera), formigas (Formicidae), piolhos de cobra (Diplopoda), tatuzinhos (Isopoda) aracnídeos (Aranaea), baratas (Blattaria), tesourinha (Dermaptera), grilos (Orthoptera), caracóis (Gastropoda), escorpiões (Scorpiones), opiliões (Opiliones), percevejos (Hemiptera), cigarras (hemíptera), larvas-de-mosca (Díptera) e mariposas (Lepidóptera) (DIAS et al., 2007; KARASAKI et al., 2013; SILVA et al., 2007). Estes indivíduos utilizam a interface solo-serrapilheiravegetação como habitat (DIAS et al., 2007; SILVA et al., 2006; SILVA et al., 2007) e em razão de seu tamanho corporal e/ou hábito comportamental, transformam o solo de modo significativo (KARASAKI et al., 2013). 
A macrofauna desempenha um papel chave no funcionamento do ecossistema, pois ocupa diversos níveis tróficos dentro da cadeia alimentar e afeta a produção primária de maneira direta e indireta (SILVA et al., 2007). Altera, por exemplo, as populações e atividade dos microrganismos responsáveis pelos processos de mineralização e humificação e, em consequência, exerce influência sobre o ciclo da matéria orgânica e a disponibilidade dos nutrientes assimiláveis pelas plantas (SILVA et al., 2006). A macrofauna também pode ser vetora de microrganismos simbióticos das plantas, como fixadores de nitrogênio e fungos micorrízicos, e é capaz de digerir, de maneira seletiva, microrganismos patogênicos (SILVA et al., 2006). Alguns organismos da macrofauna, principalmente, térmitas, formigas, minhocas e larvas de coleópteros, são denominados "engenheiros do ecossistema", pois suas atividades levam à criação de estruturas biogênicas (galerias, ninhos, câmaras e bolotas fecais), que modificam as propriedades físicas e químicas dos solos onde vivem e a disponibilidade de recursos para outros organismos (KARASAKI et al., 2013; SILVA et al., 2006). Por meio de suas ações mecânicas no solo contribuem na formação de agregados estáveis e constituem uma reserva de nutrientes potencialmente disponíveis para as plantas (SILVA et al., 2006). Outras funções da macrofauna são fragmentação do resíduo vegetal e sua redistribuição e predação de outros invertebrados (GIRACCA et al., 2003).

Fatores abióticos e bióticos podem influenciar a macrofauna edáfica (DECÄENS, 2010). Segundo Melo et al. (2009), fatores como cobertura e tipo de vegetação, topografia, clima (temperatura, umidade relativa do ar, vento, precipitação), fatores edáficos (minerais, matéria orgânica, umidade, estrutura, textura e tipo de solo) e fatores históricos (geológicos e humanos) podem afetar a diversidade e a abundância da pedofauna. No semiárido brasileiro, as condições climáticas extremas, o sobrepastejo, as queimadas e os cultivos causam distúrbios na estrutura do hábitat da pedofauna, ocasionando redução em sua abundância e diversidade (BRÉVAULT et al., 2007). Além disso, a abundância e a diversidade dos artrópodes de solo no semiárido variam em função do período sazonal da região (ARAÚJO et al., 2018; FORMIGA et al., 2018), havendo redução na abundância dos grupos menos adaptado às condições de escassez hídrica na estação seca (FORMIGA et al., 2018).

No Brasil, o número de trabalhos sobre a fauna do solo é irrelevante diante da diversidade de ecossistemas, dentro dos quais se desconhece a própria diversidade biológica do solo, o que pode acarretar a extinção de muitas espécies antes mesmo de serem conhecidas. Apesar da relevância da fauna edáfica para funcionamento dos ecossistemas, poucas pesquisas sobre os organismos da meso e macrofauna edáfica têm sido realizadas (BARETTA et al., 2006; SILVA et al., 2006; SOUTO et al., 2008), havendo, assim a necessidade de estudos que permitam uma melhor compreensão do papel dos macroinvertebrados para o equilíbrio do ecossistema solo (SOUZA et al., 2015). Neste sentido, Spiller et al. (2018) destacam que conhecer a diversidade de espécies, os serviços prestados e seu grau de interação com os ambientes que ocupam permite analisar os efeitos das modificações antrópicas sob os ecossistemas. Assim, objetivou-se identificar e classificar os diferentes grupos da macro e mesofauna do solo, estudar sua abundância e diversidade em dois períodos do ano, em um fragmento de caatinga em Redenção, Ceará. 


\section{MATERIAIS E MÉTODOS}

\section{Área de estudo}

O estudo foi desenvolvido na Fazenda Experimental Piroás (FEP), localizada no distrito de Barra Nova, em Redenção, Ceará (04014'53" S de Latitude, 3845'10" W de Longitude), pertence a Universidade da Integração Internacional da Lusofonia Afro-Brasileira (UNILAB). A mesma possui 33 hectares, sendo destinada principalmente à realização de atividades didáticas, de pesquisa e de extensão, respeitando princípios agroecológicos.

O clima da região é predominantemente tropical, com vegetação do tipo caatinga arbustiva densa e floresta subcaducifólia tropical pluvial (IPECE, 2017), com solos do tipo Planossolo Solódico e Podzólico Vermelho-Amarelo Eutrófico (CARDOSO et al., 2013). A temperatura média anual da região varia de $26^{\circ} \mathrm{C}$ a $28^{\circ} \mathrm{C}$ e a pluviosidade média anual é de $1.062,0 \mathrm{~mm}$ (IPECE, 2017), porém para os anos de 2015 e 2016, a pluviosidade anual na FEP foi de $1.229,0 \mathrm{~mm}$ e $1.096,7 \mathrm{~mm}$, respectivamente, concentrados principalmente no período de janeiro a abril, com mais de $60 \%$ da precipitação total (Figura 1).

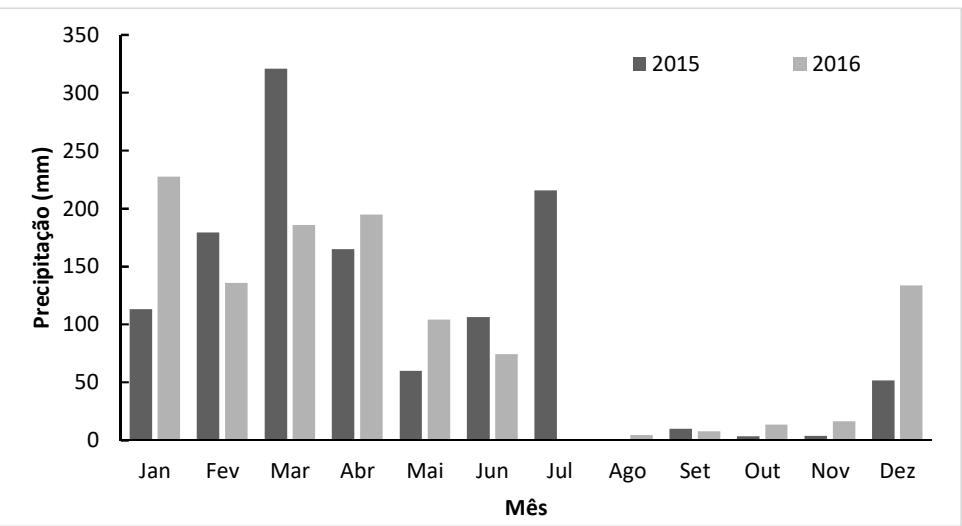

Figura 1: Precipitação pluviométrica dos anos de 2015 e 2016 na Fazenda Experimental Piroás, Redenção, Ceará.

\section{Levantamento da fauna edáfica}

O levantamento da fauna edáfica foi realizado em uma área sob vegetação nativa da caatinga em sucessão secundária a aproximadamente seis anos, após ter sido desmatada para cultivos agrícolas. Foram coletadas 72 amostras georreferenciadas por meio do equipamento de posicionamento global (GPS), uniformemente espaçados em 10 metros.

A amostragem da pedofauna (meso e macrofauna do solo) foi realizada em agosto de 2015 (período seco) e em maio de 2016 (período chuvoso). Para tal, em cada período, utilizaram-se armadilhas de queda (pitfall-traps) instaladas nos 72 pontos amostrais. As armadilhas (recipiente plástico, com capacidade para $500 \mathrm{~mL}$, enterradas no solo, com abertura ao nível da superfície) (Figura 2) foram preenchidas com líquido conservante (álcool 53\% e gotas de detergente, para quebrar a tensão superficial da água) até $\frac{1}{3}$ de sua capacidade. Após instalação, as armadilhas permaneceram no campo por 7 dias, sendo observadas a cada dois dias. Após o período de coleta as armadilhas foram levadas para o laboratório de Zoologia do Campus das Auroras da UNILAB e seu conteúdo foi transferido para solução de álcool 70\%. A identificação dos 
indivíduos presentes nas amostras foi realizada vertendo seu conteúdo em placa de Petri, observando os organismos sob microscópio estereoscópio. Os indivíduos presentes nas amostrada foram contados e separados por grupos taxonômicos (geralmente, em nível de ordem).

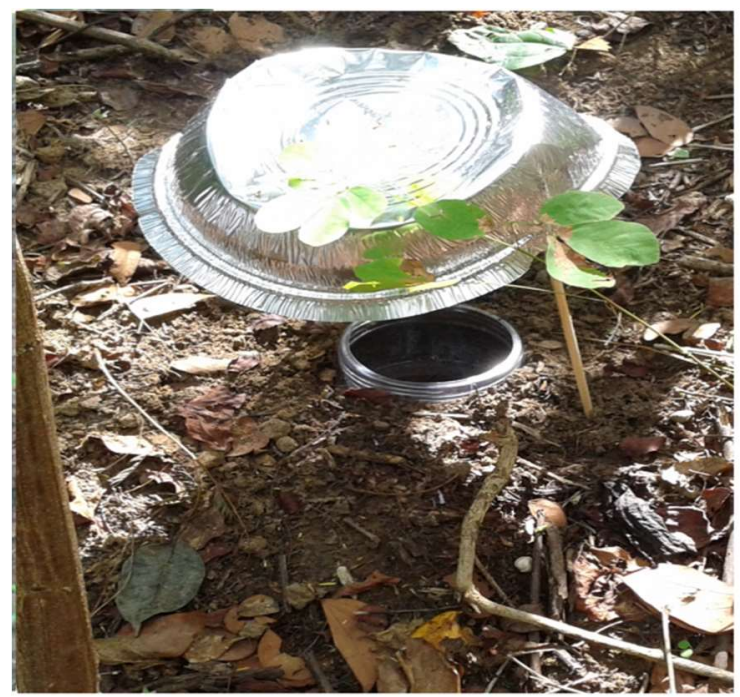

Figura 2: Armadilhas de queda tipo "pitfall-traps" instalada no solo para coleta da pedofauna, Redenção, Ceará, 20152016.

\section{Análise dos dados}

Foi calcula a frequência percentual do número de indivíduos amostrados e a abundância dos grupos em número de indivíduos por armadilha por dia (AQUINO et al., 2006). Calculou-se também, a riqueza de grupos (S), diversidade de Shannon-Weaver $\left(H^{\prime}\right)$ e uniformidade de Pielou (e). O Índice de Diversidade de Shannon-Weaver $\left(H^{\prime}\right)$, definido conforme Magurran (2004) (equação 1) é apropriado para o uso em ecologia do solo (NUNES et al., 2008), pois leva em consideração a riqueza das espécies e sua abundância relativa:

$$
H^{\prime}=-\Sigma p i . \text { Ln pi . }
$$

Em que: $\mathrm{H}^{\prime}=$ Diversidade de Shannon-Weaver em nats.ind ${ }^{-1} ; \mathrm{pi}=\mathrm{ni} / \mathrm{N} ; \mathrm{ni}=$ valor de importância de cada espécie ou grupo; $\mathrm{N}=$ total dos valores de importância.

O Índice de Uniformidade de Pielou (e'), conforme Magurran (2004) é um índice em que a uniformidade se refere ao padrão de distribuição dos indivíduos entre as espécies, sendo calculado de acordo com equação 2:

$$
\mathrm{e}^{\prime}=\frac{\mathrm{H}^{\prime}}{\log \mathrm{S}}
$$

Em que: $e^{\prime}$ = Índice de Uniformidade de Pielou; $H^{\prime}$ = Índice de Shannon; S = Número total de espécies ou grupos na comunidade.

\section{RESULTADOS E DISCUSSÃO}

No período seco (agosto de 2015) foi registrado o maior número de indivíduos da fauna edáfica, sendo observado 23515 indivíduos (Tabela 1), distribuídos em 43 grupos diferentes, enquanto no período chuvoso (maio de 2016) foram observados 18962 indivíduos (Tabela 1), distribuídos em 41 grupos distintos. Os grupos mais representativos ( $97 \%$ de todos os indivíduos amostrados) pertencem a 12 ordens, distribuídas em quatro classes (Tabela 1). 
Os grupos de menores frequências $(<1 \%)$, representado na categoria outras (Tabela 1) foram Archaeagnata, Auchenorryncha, Blattodea, Colembola, Chilopoda, Dermaptera, Diplopoda, Diplura, Embrioptera, Enchytraeidae, Gastropoda, Heteroptera, Isoptera, Larva de díptera, Larva de neuroptera, Larva de tricoptera, Larva de formicidae, lepdoptera, Mantodea, Oligochaeta, Opilionida, Plasmida, Pseudoscorpionida, Psocoptera, Pupa de Lepidóptera, Scorpionida, Sternorryncha, Symphyla, Thysanoptera, Thysanura, Tricoptera. Marques et al. (2014) ressaltam que, apesar de estes grupos muitas vezes não expressarem valores significativos, desempenham importante papel na manutenção do equilíbrio ecológico e nas relações tróficas.

Tabela 1: Número total de indivíduos amostrados e abundância (ind.arm ${ }^{-1}$.dia ${ }^{-1}$ ) da fauna edáfica amostrada na Fazenda Experimental Piroás, Redenção-CE, 2015-2016.

\begin{tabular}{|c|c|c|c|c|c|}
\hline \multirow[b]{2}{*}{ Classe } & \multirow[b]{2}{*}{ Ordem } & \multicolumn{2}{|c|}{ Total de indivíduos } & \multicolumn{2}{|c|}{ Abundância (ind.arm ${ }^{-1}$. dia $^{-1}$ ) } \\
\hline & & Período Seco & Período chuvoso & Período Seco & Período chuvoso \\
\hline \multirow[t]{2}{*}{ Arachnida } & Acarina & 1330 & 2690 & 2,64 & 5,34 \\
\hline & Araneae & 506 & 321 & 1,00 & 0,64 \\
\hline \multirow[t]{3}{*}{ Entognatha } & Entomobryomorpha & 9789 & 2389 & 19,42 & 4,74 \\
\hline & Poduromorpha & 923 & 4387 & 1,83 & 8,70 \\
\hline & Symphypleona & 882 & 0 & 1,75 & 0,00 \\
\hline \multirow[t]{9}{*}{ Insecta } & Coleoptera (adulto) & 1016 & 2472 & 2,02 & 4,90 \\
\hline & Coleoptera (Larva) & 137 & 393 & 0,27 & 0,78 \\
\hline & Dermaptera & 17 & 440 & 0,87 & 0,87 \\
\hline & Díptera & 1940 & 755 & 3,85 & 1,50 \\
\hline & Hymenoptera & 539 & 0 & 1,07 & 0,00 \\
\hline & Hymenoptera (Formicidae) & 3502 & 2905 & 6,95 & 5,76 \\
\hline & Hymenoptera (Heteroptera) & 67 & 268 & 0,13 & 0,53 \\
\hline & Lepidóptera (Larva) & 521 & 6 & 1,03 & 0,01 \\
\hline & Orthoptera & 320 & 325 & 0,63 & 0,64 \\
\hline \multirow[t]{2}{*}{ Malacostraca } & Isopoda & 235 & 168 & 0,47 & 0,33 \\
\hline & Outras & 1791 & 1443 & 3,55 & 2,86 \\
\hline Total & & 23515 & 18962 & 47,5 & 37,62 \\
\hline
\end{tabular}

A abundância total foi de 47,50 e 37,62 indivíduos por armadilha por dia nos períodos seco e chuvoso, respectivamente (Tabela 1). No período seco foi observado que as ordens que apresentam indivíduos exclusivos da mesofauna, Entomobryomorpha, Symphypleona e Acarina, destacaram-se quanto a abundância, chegando a 19,42; 1,75 e 2,64 indivíduos por armadilha por dia. Neste mesmo período os grupos da macrofauna mais abundantes foram Hymenoptera (Formicidae) (6,95 ind.arm ${ }^{-1}$. dia $\left.^{-1}\right)$, Díptera (3,85 ind. $\left.\mathrm{arm}^{-1} \cdot \mathrm{dia}{ }^{-1}\right)$ e Coleoptera $\left(2,02\right.$ ind $\left.\cdot \mathrm{arm}^{-1} \cdot \mathrm{dia}^{-1}\right)$. No período chuvoso os grupos da mesofauna, continuaram com abundância relativamente elevada, sendo que o grupo Poduromorpha destacou-se com abundância de 8,7 ind.arm ${ }^{-1} \cdot$ dia $^{-1}$, seguindo do grupo Acarina, com 5,33 ind.arm ${ }^{-1}$.dia-1 ${ }^{-1}$ e Entomobryomorpha, com 4,74 ind. $\mathrm{arm}^{-1} \cdot \mathrm{dia}^{-1}$ (Tabela 1). Hymenoptera (Formicidae) $\left(5,76\right.$ ind. $\mathrm{arm}^{-1} \cdot \mathrm{dia}^{-1}$ ) e Coleoptera $\left(4,90 \mathrm{ind}^{\mathrm{arm}}{ }^{-1} \cdot \mathrm{dia}^{-1}\right)$ foram grupos da macrofauna que se destacaram no início do período seco.

As cinco ordens mais frequentes em 2015, (Entomobryomorpha, Hymenoptera (Formicidae), Díptera, Acarina e Coleóptera (adulto)) somam 77\% dos indivíduos coletados (Figura 3A). Em 2016 houve melhor distribuição dos indivíduos entre as ordens, sendo que as cinco mais frequentes correspondem a $80 \%$ do total (Figura 3B).

As ordens Acarina, Entomobryomorpha, Poduromorpha, Coleoptera, Hymenoptera e Araneae, presentes entre os mais abundantes na Fazenda Experimental Piroás, são indicados em diversos estudos 
como potenciais bioindicadores por serem comumente amostrados, em maior abundância, em diferentes ambientes, e sob diferentes manejos e por responderem de forma rápida às alterações ambientais (MUDREK et al., 2014; SANTOS et al., 2017; SILVA et al., 2013; SILVA et al., 2015; SPILLER et al., 2018). Os ácaros (acarina) juntamente com as ordens da classe Entognatha são os principais organismos da mesofauna edáfica, desempenhando importantes funções no ecossistema ao atuarem como decompositores e facilitadores de grupos de micro-organismos (GRIESANG et at., 2016). Apresentam níveis funcionais diversos, sendo representados principalmente por predadores que regulam a microbiota e detritívoros (BROWN et al., 2015).
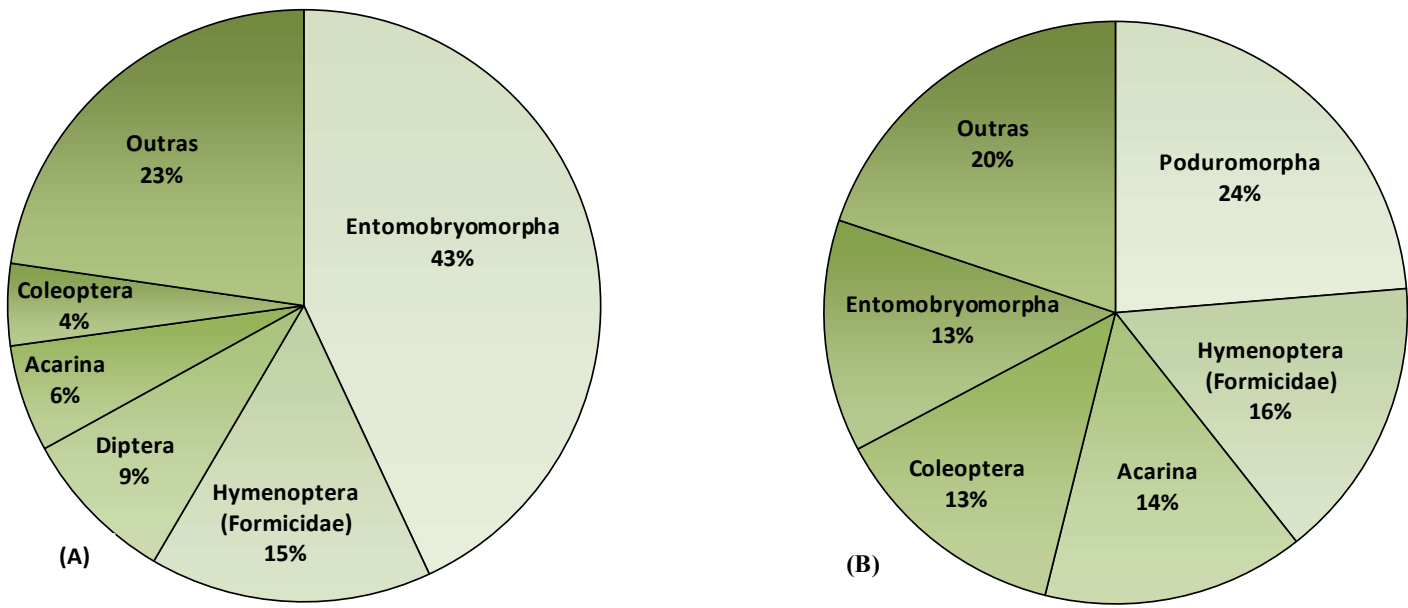

Figura 3: Composição (percentual) da pedofauna na Fazenda Experimental Piroás nos períodos seco de 2015 (A) e chuvoso de 2016 (B) em Redenção, Ceará.

Segundo Korasaki et al. (2013), o grupo Formicidae (Hymenoptera), juntamente com o Isoptera representa a maioria dos grupos da pedofauna nos solos das regiões tropicais, representando metade de sua abundância total. Estes dois grupos são grandes modificadores das características químicas e físicas do solo, sendo considerados "engenheiros do solo", tem grande diversidade de hábitos alimentares e desempenham diferentes funções no ecossistema. Baretta et al. (2010) afirmam que este grupo pode ser considerado como indicativo no ecossistema do solo, tendo em vista o nicho que ocupam, distribuem matéria orgânica e mineral em diversas camadas do solo, além das galerias que promovem aeração e infiltração da água.

No estudo realizado por Machado et al. (2015), constatou-se influência da sazonalidade sobre a dinâmica da fauna edáfica, sendo observada maior atividade de alguns grupos, como Acarina, Díptera e Entomobryomorpha, durante o período de maior precipitação, bem como a presença de determinados grupos somente no período correspondente à estação chuvosa. Entretanto, no presente estudo, alguns grupos, entre eles Díptera e Entomobryomorpha, apresentaram maior atividade no período seco, enquanto outros como Acarina e Coleoptera tiveram suas populações elevadas no período das chuvas, sendo que os grupos Symplypleona e alguns Hymenoptera só foram amostrados no período seco. A maior abundância total e de alguns grupos observada no período seco pode ter ocorrido devido à incidência atípica de elevada precipitação um mês antes da realização da coleta (Figura 1), possibilitando uma umidade do solo favorável às populações dos artrópodes do solo. Além disso, é provável que no período da coleta (início do período seco) ainda houvesse ampla disponibilidade de fontes energéticas oriunda da serapilheira, enquanto no período chuvoso, a maior parte da serapilheira depositada principalmente no período seco já havia sido 
decomposta.

Apesar de haver maior número total de indivíduos no período seco (Tabela 1), observa-se que houveram poucas modificações na composição da fauna edáfica nos dois períodos amostrado e uma distribuição mais uniforme no período chuvoso (Figura 3). Destaca-se que no período seco o grupo Entomobryomorpha representava $43 \%$ do total de indivíduos, indicando elevada dominância deste grupo, enquanto que no período chuvoso, o grupo de maior frequência, Poduromorpha, correspondeu a apenas $24 \%$ do total, indicando uma relação mais uniforme entre os grupos (Figura 3).

Observou-se que a riqueza média de grupos foi de 14,56 e 13,51, para os períodos seco e úmido, respectivamente, enquanto que a riqueza total foi 43 no período seco e 41 no período chuvoso (Tabela 2). Apesar dos resultados apontarem menores riquezas total e média no período chuvoso, neste período houve maior diversidade e equabilidade (Tabela 2), indicando uma melhor condição de equilíbrio neste período.

Tabela 2: Índices ecológicos da fauna do solo na Fazenda Experimental Piroás, Redenção-CE, 2015-2016.

\begin{tabular}{|c|c|c|}
\hline Índice & Período seco & Período chuvoso \\
\hline Riqueza média de grupos (número de grupos por armadilha) & 14,56 & 13,51 \\
\hline Riqueza total de grupos (S) & 43 & 41 \\
\hline Índice de Shannon $\left(\mathrm{H}^{\prime}\right)$ nats.ind ${ }^{-1}$ & 2,10 & 2,38 \\
\hline Índice de Pielou (e') & 0,55 & 0,63 \\
\hline
\end{tabular}

Os valores de $\mathrm{H}^{\prime}$ e e' observados neste estudo foram maiores do que os observados em outros trabalhos realizados em áreas da região semiárida, sob diferentes coberturas do solo, como matas de caatinga, áreas cultivadas após desmatamentos e queimadas, áreas em pousio após agricultura de corte e queima e sistemas agroflorestais (NUNES et al., 2008; NUNES et al.,2012; PINHEIRO et al., 2011), reforçando o indicativo de que a área estudada na Fazenda Piroás se encontrava em estado de equilíbrio. $O$ índice de equabilidade de Pielou (e') evidencia o grau de dominância numérica apresentada por um ou alguns grupos da fauna do solo. Quanto menor o valor do índice de equabilidade, maior é a dominância. Assim, o menor valor observado para este índice no período seco ocorreu devido elevada dominância dos grupos Entomobryomorpha e Formicidae (Hymenoptera), que juntos, representaram $68 \%$ do total de indivíduos amostrados.

\section{CONCLUSÕES}

A sazonalidade não alterou a composição da fauna edáfica no fragmento de caatinga estudado em Redenção, Ceará, porém, o período chuvoso favoreceu maior diversidade e equabilidade entre os grupos da pedofauna identificados.

\section{REFERÊNCIAS}

AQUINO, A. M.; CORREIA, M. E. F.; BADEJO, M. A. Amostragem de mesofauna edáfica utilizando Funis de Berlese-Tüllgren modificado. Seropédica: Embrapa Agrobiologia, 2006.

ARAÚJO, J. L.; PASTORI, P. L.; GOMES, V. F. F.; MENDES FILHO, P. F.; NUNES, L. A. P. L.. Changes in the abundance and diversity of soil arthropods in the cultivation of fruit crops. Revista Ciência Agronômica, v.49, n.4, p.537-546, 2018.

BARETTA, D.; MAFRA, A. L.; SANTOS, J. C. P.; AMARANTE, C. V. T.; BERTOL, I.. Análise multivariada da fauna edáfica em diferentes sistemas de preparo e cultivo do solo. Pesquisa Agropecuária Brasileira, v.41, n.11, p.1675-1679, 2006. 
BRÉVAULT, T.; BIKAY, S.; MALDE'S, J. M.; NAUDIN, K.. Impact of a no-till with mulch soil management strategy on soil macrofauna communities in a cotton cropping system. Soil \& Tillage Research, v.97, p.140-149, 2007.

BROWN, G. G.; NIVA, C. C.; ZAGATTO, M. R. G.; FERREIRA, S. A.; NADOLNY, H. S.; CARDOSO, G. B. X.; SANTOS, A.; MARTINEZ, G. A.; PASINI, A.; BARTZ, M. L. C.; SAUTTER, K. D.; THOMAZINI, M. J.; BARRETA, D.; SILVA, E.; ANTONIOLLI, Z. I.; DECAENS, T.; LAVELLE, P. M.; SOUZA, J. P.; CARVALHO, F. Biodiversidade da fauna do solo e sua contribuição para os serviços ambientais. In: PARRON, L. M.; GARCIA, J. R.; OLIVEIRA, E. B.; BROWN, G. G.; PRADO, R. B.. Serviços ambientais em sistemas agrícolas e florestais do bioma Mata Atlântica. Brasília: Embrapa, 2015.

CARDOSO, E. R. C.; FRETES, T. O.; SILVA, F. N.. Levantamento e mapeamento geofísico da Fazenda da Unilab em Redenção, CE. Universidade da Integração Internacional da Lusofonia Afro-Brasileira, 2013.

DECÄENS, T.. Macroecological patterns in soil communities. Global Ecology and Biogeography, v.19, p.287-302, 2010.

DIAS, P. F.; SOUTO, S. M.; CORREIA, M. E. F.; RODRIGUE, K. M.; FRANCO, A. A.. Efeito de leguminosas arbóreas sobre a macrofauna do solo em pastagem de Brachiaria brizantha cv. Marandu. Pesquisa Agropecuária Tropical, v.37, n.1, p.3844, 2007.

FORMIGA, L. D. A. S.; PAULO, P. F. M.; SANTOS, A. M. S.; CASSUCE, M. R.; LIMA, L. B.; SANTOS, M. F. S.. Distribuição temporal da macrofauna edáfica em áreas de caatinga sob pastejo caprino. Revista Eletrônica Acervo Saúde, v.10, n.2, p.1551-1559, 2018

GIRACCA, E. M. N.; ANTONIOLLI, Z. I.; ELTZ, F. L. F.; BENEDETTI, E.; LASTA, E.; VENTURINI, S. F.; VENTURINI, E. F.; BENEDETTI, T.. Levantamento da meso e macrofauna do solo na microbacia do Arroio Lino, Agudo / RS. Revista Brasileira de Agrociência, v.9, n.3, p.257-261, 2003.

GRIESANG, F.; LOPES-SILVA, V.; WILDNER, L. P.; SORDI, R.. Influencia do cultivo de adubos verdes na dinâmica populacional da mesofauna edáfica em áreas manejadas sob plantio direto. Revista Brasileira de Agroecologia, v.11, n.2, p.70-78, 2016.

IPECE. Instituto de Pesquisa e Estratégia Econômica Do Ceará. Perfil Básico do Município - Redenção. IPECE, 2017.

KORASAKI, V.; MORAIS, J. W.; BRAGA, R. F.. Macrofauna. In: MOREIRA, F. M. S.; CARES, S. J.; ZANETTI, R.; STURMER, S. L. O ecossistema solo: componentes, relações ecológicas e efeitos na produção. Lavras: UFLA, 2013.

LIMA, S. S.; AQUINO, A. M.; LEITE, L. F. C.; VELÁSQUEZ, E.; LAVELLE, P.. Relação entre macrofauna edáfica e atributos químicos do solo em diferentes agroecossistemas. Pesquisa Agropecuária Brasileira, v.45, n.3, p.322-331, 2010.

MACHADO, J. P.; OLIVEIRA FILHO, L. C. I.; KROLOW, I. R. C.; KROLOW, D. V.; MORSELLI, T. B. A.. Avaliação da mesofauna (ácaros e colêmbolos) sob plantio direto em uma forrageria de inverno. Revista Brasileira de Agroecologia, v.2, n.1, p.557-561, 2007.
MACHADO, D. L.; PEREIRA, M. G.; CORREIA, M. E. F.; DINIZ, A. R.; MENEZES, C. E. G.. Fauna edáfica na dinâmica sucessional da mata atlântica em floresta estacional semidecidual na bacia do rio Paraíba do Sul - RJ. Ciência Florestal, v.25, n.1, 91-106, 2015.

MAGURRAN, A. E.. Measuring Biological Diversity. Oxford: Blackwell Science Ltd, 2004

MELO, F. V.; BROWN, G. G.; CONSTANTINO, R.; LOUZADA, J. N. C.; LUIZÃO, F. J.; MORAIS, J. W.; ZANETTI, R. A.. Importância da meso e macrofauna do solo na fertilidade e como biondicadores. Boletim Informativo da SBCS. Visoça: SBCS, 2009.

MARQUES, D. M.; SILVA, A. B.; SILVA, L. M. S.; MOREIRA, E. A.; PINTO, G. S.. Macrofauna edáfica em diferentes coberturas vegetais. Biosci. J., v.30, n.5, p.1588-1597, 2014.

MOÇO, M. K. S.; GAMA-RODRIGUES, E. F.; GAMARODRIGUES, A. C.; CORREIA, M. E. F.. Caracterização da fauna edáfica em diferentes coberturas vegetais na Região Norte Fluminense. Revista Brasileira de Ciência do Solo, v.29, p.555-564, 2005.

MORAIS, J. W.; OLIVEIRA, F. G. L.; BRAGA, R. F.; KORASAKI, V.. Mesofauna. In: MOREIRA, F. M. S.; CARES, S. J.; ZANETTI, R.; STURMER, S. L.. O ecossistema solo: componentes, relações ecológicas e efeitos na produção. Lavras: Ed UFLA, 2013.

MUDREK, J. R.; MASSOLI JUNIOR, E. V.. Estrutura da comunidade de artrópodes de solo em diferentes fitofisionomias da reserva particular do patrimônio natural SESC Pantanal, Brasil. Holos, v.30, n.1, p.60-67, 2014.

NUNES, L. A. P. L.; ARAÚJO FILHO, J. A.; MENEZES, R. I. Q.. Recolonização da fauna edáfica em áreas de Caatinga submetidas a queimadas. Revista Caatinga, v.21, n.3, 214 220, 2008.

NUNES, L. A. P. L.; SILVA, D. I. B.; ARAÚJO, A. S. F.; LEITE, L. F. C.; CORREIA, M. E. F.. Caracterização da fauna edáfica em sistemas de manejo para produção de forragens no Estado do Piauí. Revista Ciência Agronômica, v.43, n.1, p.0-37, 2012.

PINHEIRO, F. J.; ALVES, T. S.; ALMIR, J. P. S.; RAULINO, F. E. S.; FIALHO, J. S.; AGUIAR, M. I.. Fauna edáfica como bioindicadora do manejo agrícola no semiárido cearense. Cadernos de Agroecologia, v.6, n.2, 2011.

SANTOS, D. P.; SCHOSSLER, T. R.; SANTO, I. L.; MELO, N. B.; SANTOS, G. G.. Soil macrofauna in a Cerrado/Caatinga ecotone under different crops in Southwestern Piauí State, Brazil. Ciência Rural, v.47, n.1. p.2-9, 2017.

SILVA, R. F.; AQUINO, A. M.; MERCANTE, F. M.; GUIMARÃES, M. F.. Macrofauna invertebrada do solo sob diferentes sistemas de produção em Latossolo da Região do Cerrado. Pesquisa Agropecuária Brasileira, v.41, n.4, p.697-704. 2006.

SILVA, J.; CASALINHO, H.; VERONA, L. E.; SCHWENGBER, J.. Avaliação da mesofauna (colêmbolos e ácaros) do solo em agroecossistemas de base familiar no Rio Grande do Sul. Revista Brasileira de Agroecologia, v.2, n.2, p.539-542, 
2007.

SILVA, R. F.; CORASSA, G. M.; BERTOLLO, G. M.; SANTI, A. L.; STEFFEN, R. B.. Fauna edáfica influenciada pelo uso de culturas e consórcios de cobertura do solo. Pesquisa Agropecuária Tropical, v.43, n.2, p.130-137, 2013.

SILVA, B. A.; FREITAS, C. C.; MELO, J. L. M.; LIMA, S. M. S.; AGUIAR, M. I.. Macrofauna edáfica em áreas de policultivo $e$ mata nativa na Fazenda Experimental da UNILAB. Anais do Congresso Brasileiro de Ciências do Solo, Natal, RN, Brasil, 35, 2015.
SOUTO, P. C.; SOUTO, J. S.; MIRANDA, J. R. P.; SANTOS, R. V.; ALVES, A. R.. Comunidade microbiana e mesofauna edáficas em solo sob caatinga no semi-árido da Paraíba. Revista Brasileira de Ciência do Solo, v.32, n.1, p.151-160, 2018.

SOUZA, M. H.; VIEIRA, B. C. R.; OLIVEIRA, A. P. G.; AMARAL, A. A.. Macrofauna do solo. Enciclopédia Biosfera, v.11, n.22, p.115-131, 2015

SPILLER, M. S.; SPILLER, C.; GARLET, J.. Arthropod bioindicators of environmental quality. Revista Agro@mbiente On-line, v.12, n.1, p.425-441, 2018. 